\title{
IoT Enabled Air Pollution Monitoring System
}

\author{
P Chenchu Sai Babu, Bhamini Banerjee, Kumar Shubham, CR Srinivasan
}

\begin{abstract}
Air Pollution is the major problem that we are facing now-a-days. Controlling air pollution in an area is becoming difficult and many people are facing a lot of health issues due to this increased pollution rates in the country. The increased amount of carbon monoxide (CO), smoke, carbon dioxide (CO2) have lead a severe impact on the human life. The growing number of vehicles and industries contributes to air pollution to a greater extent. This paper presents a model which helps in monitoring the air pollution through the use of internet of things (IoT) platform. Implementing it with sensors and arduino which will help the user to know about the temperature and the humidity level on the smart phone and accordingly the user can take preventive measures. Also the system detects air quality and if the amount of pollutants increased."
\end{abstract}

Keywords: Air monitoring system, Arduino, Internet of Things(IoT), Sensor, Thing Speak, Wifi module.

\section{INTRODUCTION}

Presently multi day's contamination from engine vehicles has turned into the most perceived air quality issue. Present situation contamination checking uncovers that on the off chance that we don't think and act mindfully, at that point vehicle contamination could hurt nature in which we are living and lessen the personal satisfaction for who and what is to come. Individuals should be urged to utilize open transport or offer vehicles at whatever point conceivable so just the base measure of contamination is made.

"We are utilizing the idea of Internet of things(IoT) in our undertaking to screen the air contamination of a specific territory. Fundamentally Internet of things is a system of physical items that comprise of sensors, programming and equipment which can speak with one another just as the clients. One of the use of IoT is in the savvy city that guarantees to improve the nature of air contamination and execution of urban administrations. It likewise helps in upgrading the way of life of the residents by giving better offices and also diminishes the endeavors for the administration of the city by empowering powerful use of assets.

The remaining paper is organized as follows, Section 2 deals with literature review, and Section 3 deals with project description. The methodology used in the suggested system is briefed in Section 4. Results obtained is given in Section 5 followed by Section 6 which deals with conclusion and future scope.

Revised Version Manuscript Received on 10 September, 2019.

P Chenchu Sai Babu, Manipal Institute of Technology, Manipal Academy of Higher Education, Manipal, Karnataka, India.

Bhamini Banerjee, Manipal Institute of Technology, Manipal Academy of Higher Education, Manipal, Karnataka, India.

Kumar Shubham, Manipal Institute of Technology, Manipal Academy of Higher Education, Manipal, Karnataka, India.

CR Srinivasan, Manipal Institute of Technology, Manipal Academy of Higher Education, Manipal, Karnataka, India.

\section{LITERATURE REVIEW}

"IoT based Air Pollution Monitoring System screens the Air Quality over a web server using web and will trigger an alert when the air quality goes down past a particular measurement, suggests when there are total of dangerous gases present recognizable all around like $\mathrm{CO} 2$, smoke, alcohol, benzene, NH3, NOx and LPG. The system will show the air quality in PPM on the LCD and similarly as on site page with the objective that it might be checked in all respects successfully. Temperature and Humidity is perceived and saw in the system.[1]"

"The authors Ray and ParthaPratim proposed a technique which can measure $2.5 \mu \mathrm{m}$ particulate matter in a smarter way. Internet of Things (IoT) based cloud services has been incorporated to analyze the measured data in cloud servers. An optical sensor is coordinated with the framework which empowers the client to imagine the thickness dimension of particulate issues progressively. Sequential yield enables the client to screen the procedure of catch the information, arrange availability and information transmission towards the cloud.[2] “

A surrounding of a constant real time air quality monitoring system is presented by Kadri Abdullah. The system comprises of a few dispersed monitoring station that discuss remotely with a backend server utilizing machine-to-machine correspondence. Each station is equipped with humidity and temperature sensor just as information logging and remote correspondence capacities. The backend server gathers continuous information from the system and changes over it into data conveyed to clients through online interfaces and portable devices. [3]

The authors Khodve, Shilpa R. and A. N. Kulkarni has given an insight of a system which will have ARM7 LPC2138 which is the heart of the system. Sensors like gas sensors, temperature, humidity etc. are interfaced with the microcontroller for the air pollution monitoring system. The obtained values are given to smart phone using Bluetooth.[4]

The portable framework for air quality also, contamination estimation appropriate for the urban condition has been explained in a paper by Tudose. Continuous assembled information can be openly gotten to by general society through an internet web interface. Applicants can select and see diverse gases and fixations covered on a guide of the place.[5]

\section{MATHEMATICAL ANALYSIS OF THE SYSTEM}

The level of concentration of pollutants in the air is measured in parts per millions (ppm) or percentage.

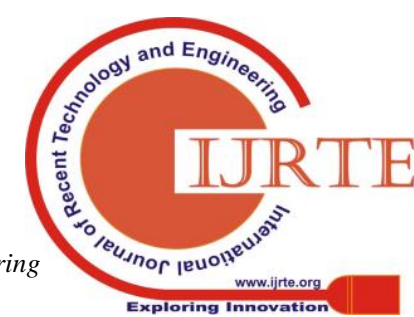


Conversion factors include the following:

$1 \mathrm{ppm}=1.145 \mathrm{mg} / \mathrm{m} 3$

$1 \mathrm{mg} / \mathrm{m} 3=0.873 \mathrm{ppm}$

$1 \mathrm{ppm}=1 / 1000000$

$1 \mathrm{ppm}=0.0001 \%$

\begin{tabular}{|c|c|}
\hline Parts per million(ppm) & Percentage(\%) \\
\hline 0 & 0 \\
\hline 5 & 0.005 \\
\hline 50 & 0.005 \\
\hline 500 & 0.05 \\
\hline 1000 & 0.1 \\
\hline
\end{tabular}

Table 3.1 PPM to Percentage conversion

\section{METHODOLOGY}

"The system comprises of Aruduino microcontroller, humidity and temperature sensor, gas sensor and a Wifi module. In this paper, we are proposing a model which will screen and control the air pollution level along with humidity and temperature which is given out from the vehicles and industries. We are using MQ135 gas sensor which will recognize $\mathrm{CO} 2$, smoke and many more harmful gases. Simultaneously it will identify the proportion of gas it will send this information to Arduino. DHT11 is a temperature and humidity sensor which gives information to the Arduino. In case the level of polluting gas is more than the level required it will send an alert to the user through smart phone. We have used buzzer and an led which will detect the level and beep accordingly or the Led will glow if the level rises the certain level

The paper goes for planning an air pollution observing framework which can be introduced in a particular region and to improve the framework from the recently created frameworks beating the prior disservices by building up an android application accessible for the general population. This application can be utilized by anybody to get in live updates about the contamination in their district.[6]"

\subsection{Arduino Microcontroller}

Arduino is an open-source gadgets stage dependent on simple to-utilize equipment and software.Arduino sheets can peruse inputs - light on a sensor, a finger on a catch and transform it into a yield turning on a LED.Through the Arduino board we can get a hint of what to do by sending a set of instructions to the microcontroller on the board and for this we use programming language which is basically ame as (IDE), based on processing. This microcontroller can work with various communication technologies and sensors. Due to its simplicity and availability of number of hardware extensions, the board can be used with utmost efficiency.[7]
$1 \%=1 / 100$ $\mathrm{C}$ programming and also we can use the Arduino Software

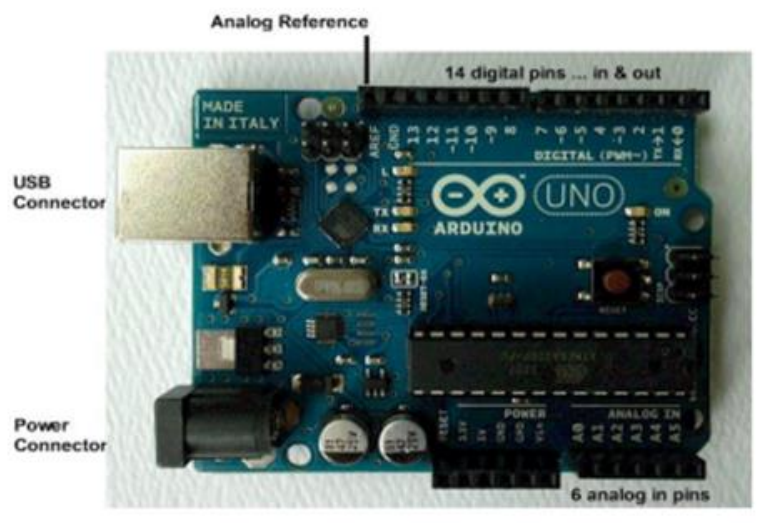

Figure 4.1 Arduino microcontroller

\begin{tabular}{|c|c|c|}
\hline Pin Category & Pin Name & $\begin{array}{c}\text { Details } \\
\end{array}$ \\
\hline Power & $\begin{array}{c}\text { Vin, } 3.3 \mathrm{~V}, 5 \mathrm{~V}, \\
\text { GND }\end{array}$ & $\begin{array}{l}\text { Vin: Input voltage to Arduino when using an external } \\
\text { power source. } \\
\text { 5V: Regulated power supply used to power } \\
\text { microcontroller and other components on the board. } \\
\text { 3.3V: } 3.3 \mathrm{~V} \text { supply generated by on-board voltage } \\
\text { regulator. Maximum current draw is } 50 \mathrm{~mA} \text {. } \\
\text { GND: ground pins. }\end{array}$ \\
\hline Reset & Reset & Resets the microcontroller. \\
\hline Analog Pins & $\mathrm{A} 0-\mathrm{A} 5$ & Used to provide analog input in the range of $0-5 \mathrm{~V}$ \\
\hline Input Output Pins & Digital Pins $0-13$ & Can be used as input or output pins. \\
\hline Serial & $0(\mathrm{Rx}), 1(\mathrm{Tx})$ & Used to receive and transmit TTL serial data. \\
\hline External Interrupts & 2,3 & To trigger an internupt. \\
\hline PWM & $3,5,6,9,11$ & Provides 8-bit PWM output. \\
\hline SPI & $\begin{array}{c}10 \text { (SS), } 11 \text { (MOSI) } \\
12 \text { (MISO) and } 13 \\
\text { (SCK) }\end{array}$ & Used for SPI communication. \\
\hline Inbuilt LED & 13 & To tum on the inbuilt LED. \\
\hline TWI & $\begin{array}{l}A 4(\mathrm{SDA}), \mathrm{A}^{5} \\
(\mathrm{SCA})\end{array}$ & Used for TWI communication. \\
\hline AREF & AREF & To provide reference voltage for input voltage. \\
\hline
\end{tabular}

Table 2: Pin description of Arduino

\subsubsection{Wifi module}

"The Wifi module we are using in this model is NodeMCU. It is an open source IoT platform. It is a SoC( System on a chip) produced by Espress-if Systems, and hardware which is based on the ESP-12 module. The meaning of the term NodeMCU by default refers to the firmware rather than the development kits. The Lua scripting language is used by the firmware. It can be programmed directly through USB port using LUA programming or Arduino IDE.[8]"

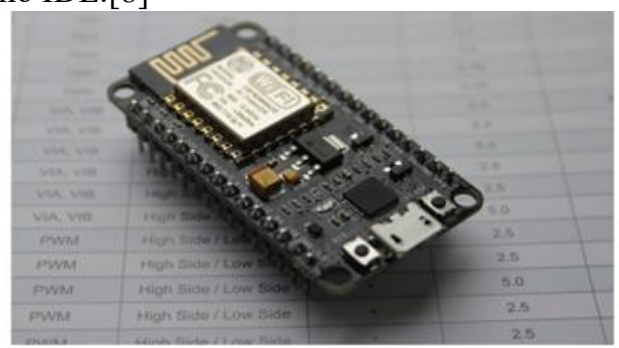

Figure 4.2 WifimoduleNodeMCU

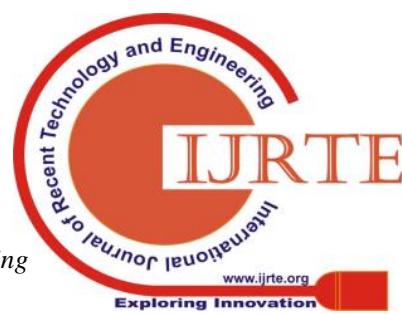




\subsubsection{Gas Sensor (MQ135)}

MQ135 is a gas sensor which utilizes a touchy material to be specific $\mathrm{SnO} 2$. The conductivity of this material is lower in clean air. The sensor conductivity increments with the can screen various types of harmful gases, for example, smelling salts gas, benzene arrangement steam and $\mathrm{CO} 2$. The identification extend is $10-10,000 \mathrm{ppm}$ with the voltage rate of about $5.0 \mathrm{~V} \pm 0.1 \mathrm{~V}$ AC or DC. Sensitive material of the sensor is tin-dioxide, whose conductivity increments with the grouping of gas. The sensor MQ135 is exceptionally sensitive to alkali, sulfide and benzene steams, smoke and other unsafe gases. It is an ease sensor, reasonable for various applications. Yield of the gas sensor is associated with simple information stick A3 of Arduino Uno board through connector CON2.

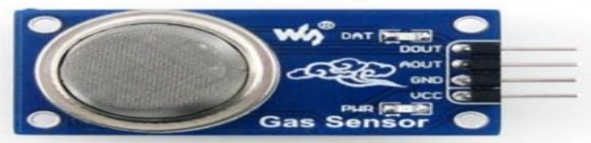

Figure 4.3 MQ135 Gas Sensor

\section{Pin Description}

- 1 , the VDD power supply 5V DC

- 2 GND, used to connect the module to system ground.

- 3 DIGITAL OUT, You can also use this sensor to get digital output from this pin, by setting a threshold value using the potentiometer

- 4 ANALOG OUT, This stick yields 0-5V simple voltage dependent on the power of the gas. [9]

\subsubsection{Temperature and Humidity sensor (DHT11)} estimation part and a NTC temperature estimation segment. It associates with a superior 8-bit microcontroller, offering incredible quality, quick reaction, hostile to obstruction capacity and cost-adequacy. Every component of DHT11 is carefully aligned in the lab that is very precise on mugginess calibration.The single-wire sequential interface makes the framework combination snappy and simple. Its little size, low power utilization and up-to-20 meter flag transmission settling on it the best decision for different applications, including those most requesting ones. The part is 4-stick single line stick bundle[10]."

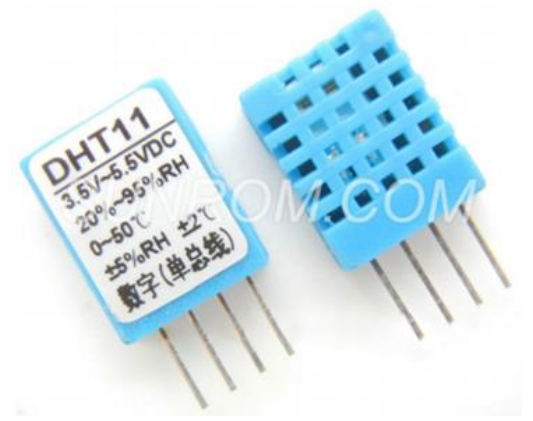

Figure 4.4 DHT11 sensor expanding centralization of target contamination gas. This

"DHT11 sensor incorporates a resistive-type moistness

\subsubsection{Thing Speak}

"Thing Speak is a cloud platform for Internet of Things. It allows the users to store the data collected from sensors in different channels. It is also used for real-time data processing, visualizations, and plugins. The gadget or application can speak with ThingSpeak utilizing a RESTful API, and we can either keep the information private, or make it open. What's more, we use ThingSpeak to dissect and follow up on the required information.[11]"

\subsection{Block diagram of the proposed system}

The model consist of Arduino which is the heart of the project. Gas sensor MQ135 and DHT11 which is a temperature and humidity sensor. Both the sensors are connected to the Arduino which is connected to the computer or smart phone.

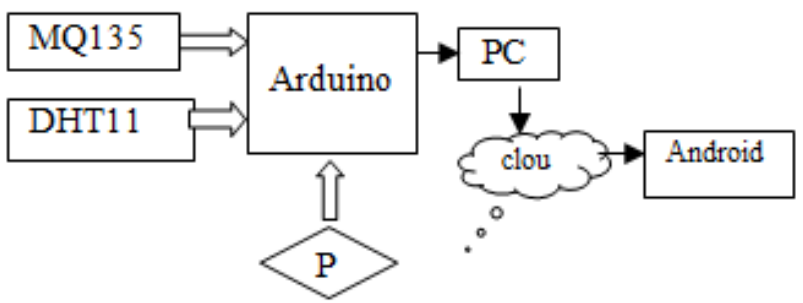

Figure 4.1 Block diagram of the processed model

The user can install android app on their phone to get updates regarding the status of the air pollution near their place.

We are also using Wifi module, NodeMCU which receives data from the Arduino and send it to internet which we can read on smart phone or laptop from anywhere.

The gas sensor MQ135 detects all the harmful gases such as ammonia, carbon monoxide (CO), methane, smoke etc.

DHT11, temperature and humidity sensor to helps us to know the water vapour content in that particular temperature and helps in taking the necessary precaution."

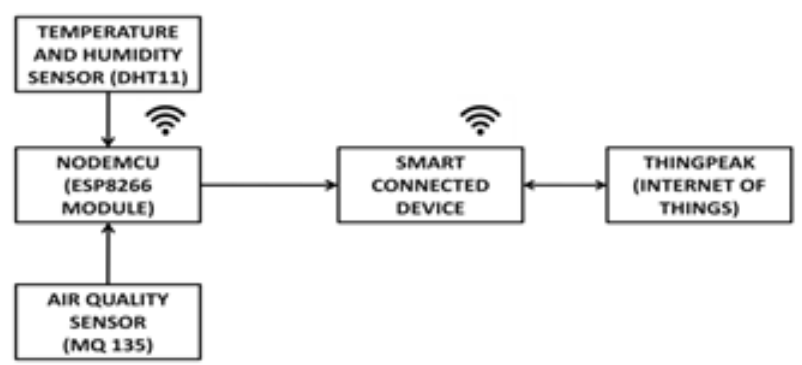

Figure 4.2 Block Diagram of sending data to Thing Speak through NODEMCU

\section{RESULTS}

"The results obtained from the project is that the concentration of the each gas measured using various sensors are observed through the serial monitor of Arduino. Further the data will be obtained in the respective Thing Speak network and this data will be available in live for monitoring.

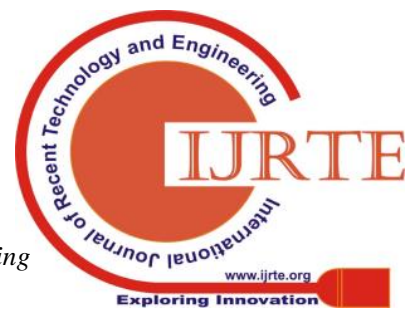




\section{IOT ENABLED AIR POLLUTION MONITORING SYSTEM}

Also we have seen that the level of temperature and humidity alonf with the pollution level can be seen in the Thing speak website."

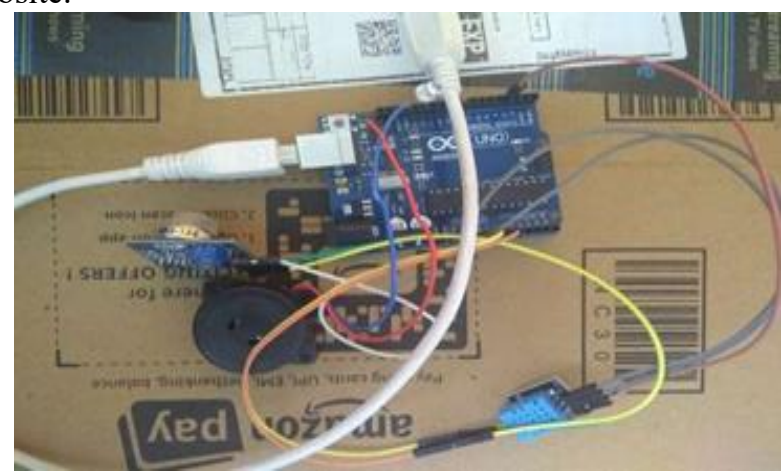

Figure 5.1 Circuit Diagram

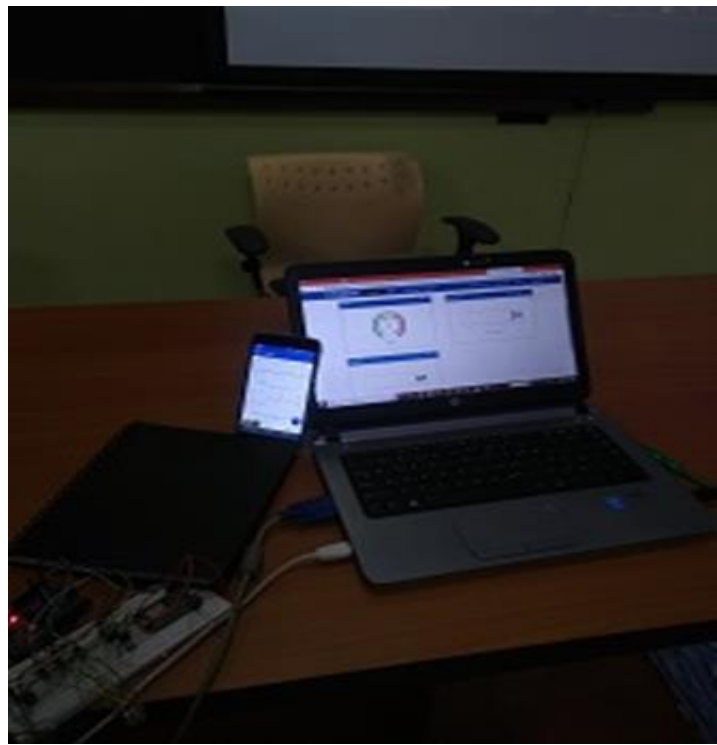

Figure 5.2 The working system along with PC

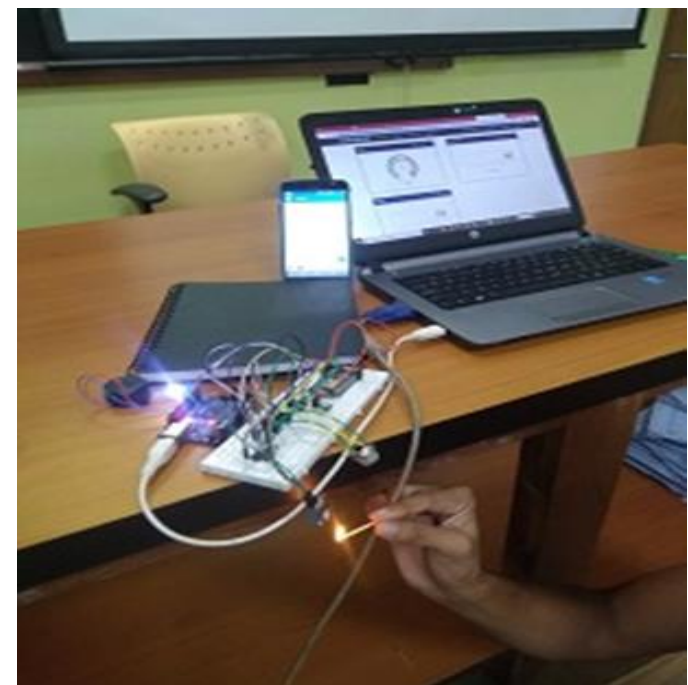

Figure 5.3 Showing when matchstick is burn and smoke is released

\subsection{Graphical Diagrams and Explanation}

By observing the following parameters, the results are as follows:

\section{TEMPERATURE}

From these graph we observe that in Fig.5.1.1 the Room temperature which is measured by the DHT11 Sensor is approximetly 27 degree celcius and from Fig5.1.2.

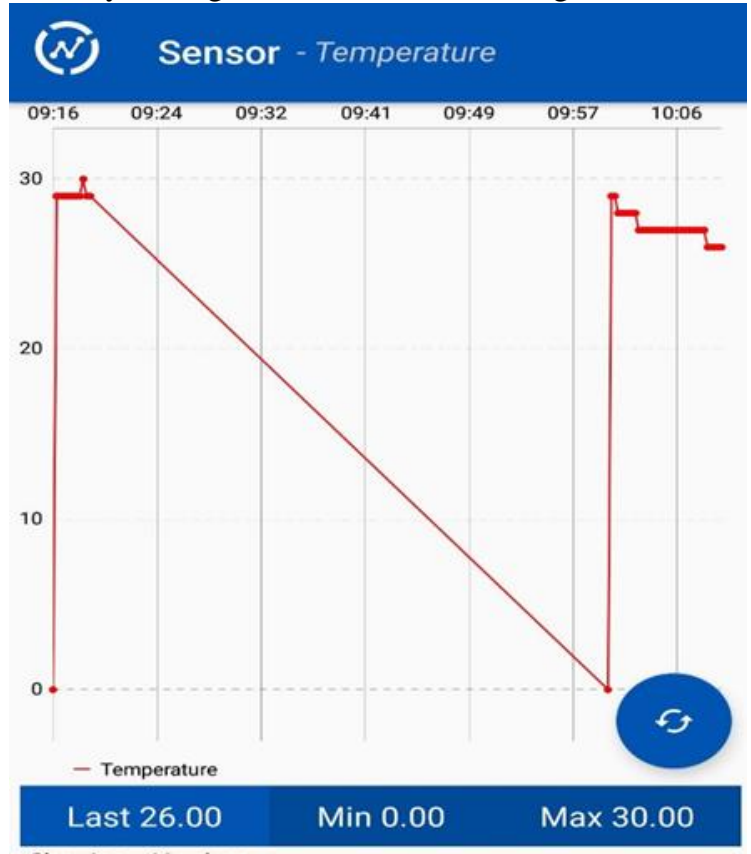

Showing 46 values

Fig.5.1.1 Graphical representation of Room Temperature

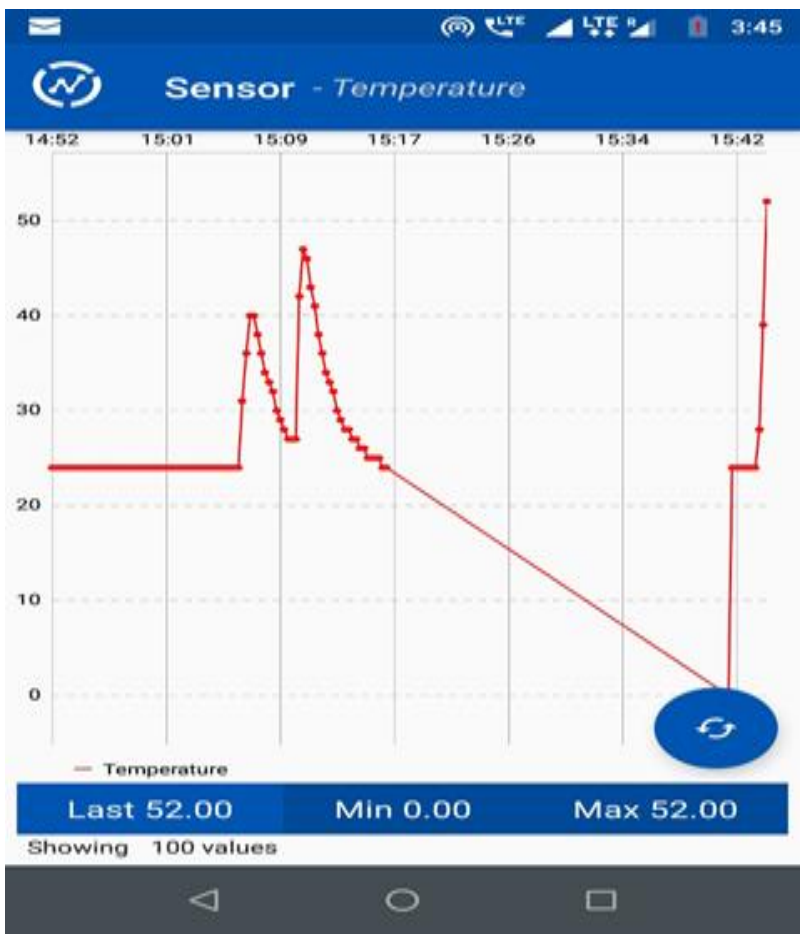

Fig5.1.2 Graphical representation of Outside Temperature

The Outside temperature measured DHT11 is 38 degree celcius which is taken from paticular area. We can observe from the graph of Fig.5.1.2 that the temperature is increasing as the Sensor start heating up.

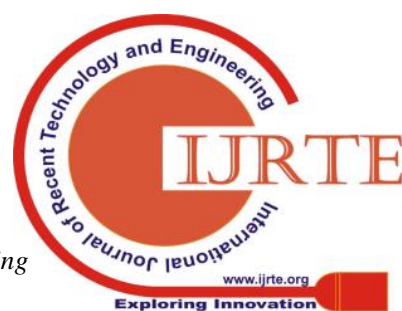




\section{HUMIDITY}
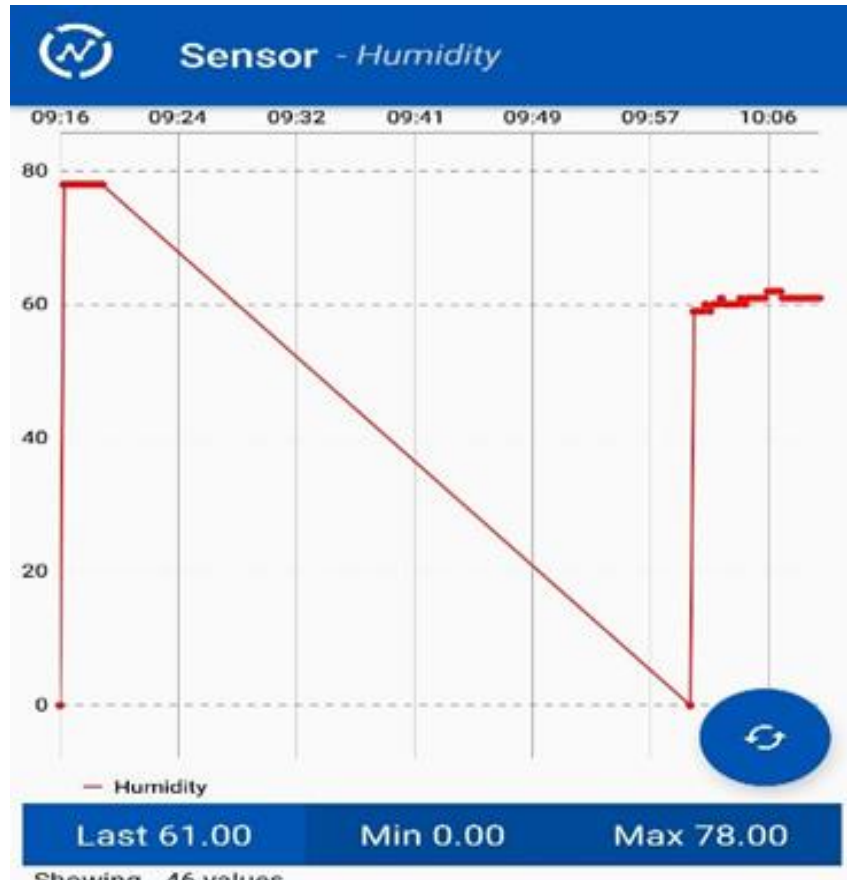

Showing 46 values

Fig.5.1.3. Graphical representation of Humidity in a room

\section{Sensor}

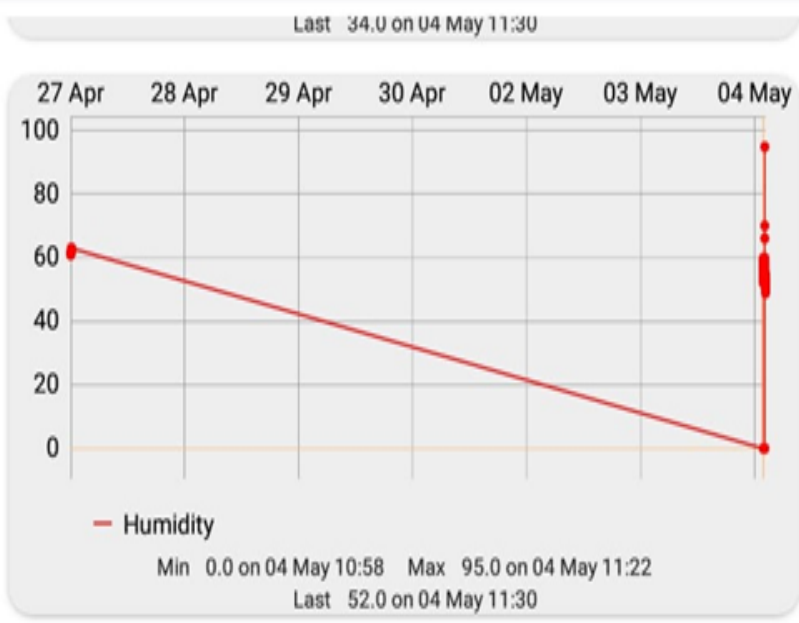

Fig5.1.4.Graphical representation of Humidity in an outside area.

From these graphs we can observe the level of humidity which is varying as the temperature increases or decreses. Fig.5.1.3.is the graphical representation of humidity which is taken in room by using DHT11 Sensor and Fig5.1.4.is the graphical representation of humidity which is taken from particular area.

\section{SMOKE}

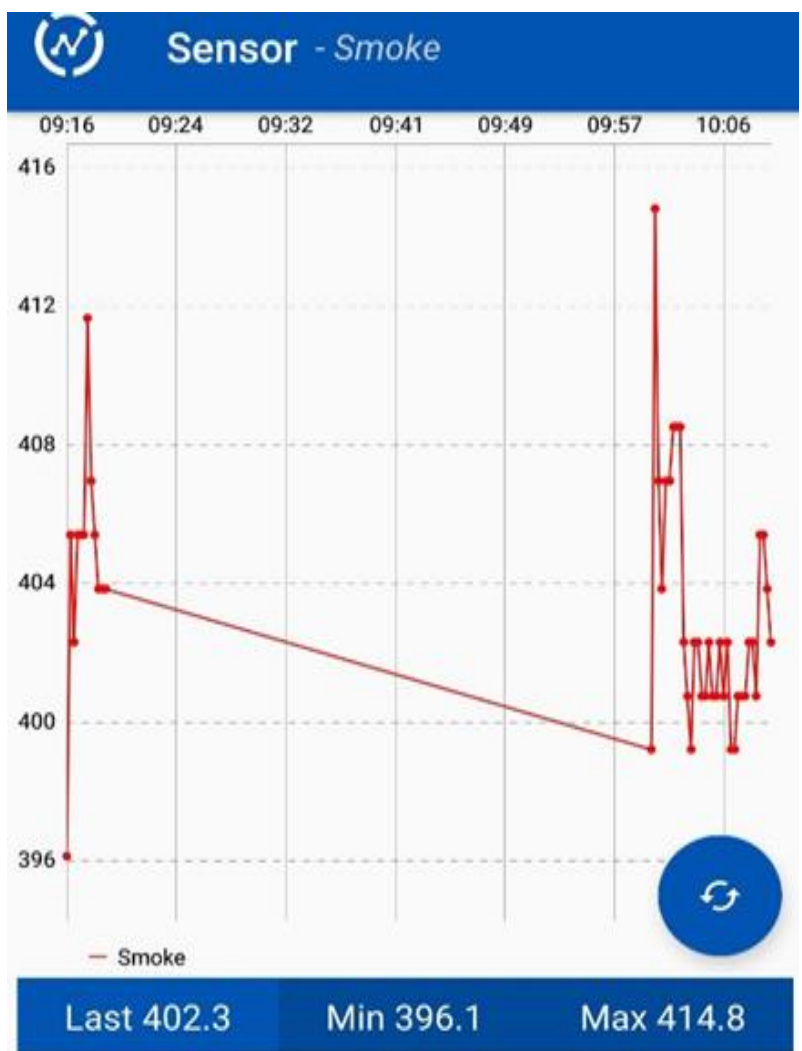

Showing 46 values

Fig.5.1.5. Graphical representation of Smoke inside a room.

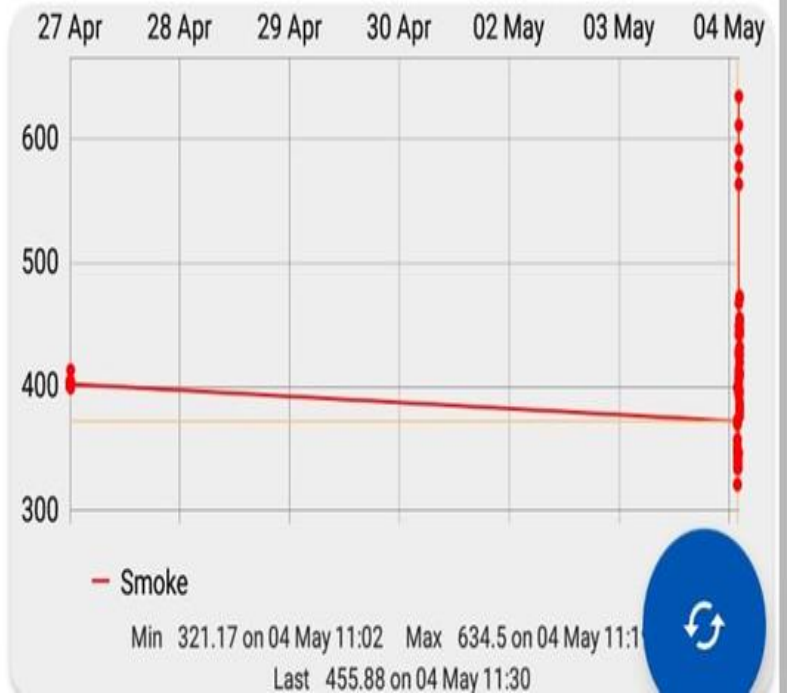

Fig.5.1.6. Graphical representation of Smoke outside.

From these graphs we can observe the $\mathrm{Co} 2$ value in the unit6 of PPM. Fig.5.1.5 showing the graphical representation of smoke which is taken in the room. The PPM value which we got in the room is approx 390, which increases if someone exhale Co2 in front of MQ135 Sensor or light the match in front of Sensor.Fig.5.1.6. showing graphical representation of smoke in polluted area.

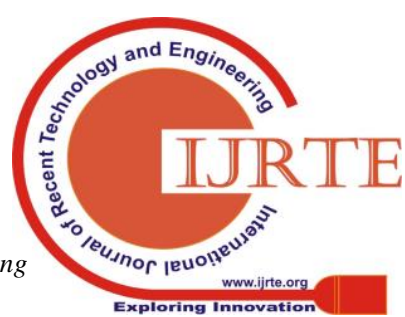




\section{IOT ENABLED AIR POLLUTION MONITORING SYSTEM}

\section{CONCLUSION AND FUTURE SCOPE}

This framework survives the issue of contamination observing, wellbeing checking, occupation estimation, maintainability evaluations and estimation related fields. The information's are consequently put away in the database; this data can be utilized by the experts to take brief activities. It likewise helps the ordinary individuals to think about the measure of poisons in their general vicinity also, to take control measures.

This is a powerful framework which is helpful in ventures as a result of the expanding contamination because of increment in enterprises. This framework is client benevolent and cost of the item is moderate. This framework is checking just five parameters and consequently can be extended by considering more parameters that cause the contamination particularly by the ventures. Numerous poisons don't have sensors that sense them if accessible they are extravagant and henceforth constructing sensors for distinctive parameters may be a future and extremely testing task. The model devours an excess of intensity, so we can utilize sun oriented power as an outside wellspring of vitality in future and it will improve the unwavering quality of the framework.

\subsection{Future Scope}

- "Interface progressively number of sensors to realize detail substance of the considerable number of gases present noticeable all around.

- Plan web page and transfer information on web page with information and time.

- Interface any storage devices to save data.

- Interface GPS module to screen contamination at accurate area and transfer on the site page for the residents.

\section{REFERENCES}

1. World Health Organization, "Monitoring ambient air quality for health impact assessment," WHO Regional Office Eur, Copenhagen, Denmark,Tech.Rep.85,1999

2. Ray, ParthaPratim. "Internet of Things Cloud based smart monitoring of Air Borne PM2. 5 density level." Signal Processing, Communication, Power and Embedded System (SCOPES), 2016 International Conference on. IEEE, 2016.

3. Kadri, Abdullah, et al. "Wireless sensor network for realtime air pollution monitoring." Communications, Signal Processing, and their Applications (ICCSPA), 2013 1st International Conference on. IEEE, 2013.

4. Khodve, Shilpa R., and A. N. Kulkarni. "Web Based Air Pollution Monitoring System (Air Pollution Monitoring Using Smart Phone)." International Journal of Science and Research (IJSR) 5.3 (2016): 266-269.

5. Tudose, Dan Stefan, et al. "Mobile sensors in air pollution measurement. "Positioning Navigation and Communication (WPNC), 2011 8th Workshop on. IEEE, 2011.

6. Ms. SarikaDeshmukh, Mr.Saurabhsurendran and Prof.M.P. Sardey:Air and Sound Pollution Monitoring System using IoT Volume: 5 Issue:

7. Marin B. Marinov, Ivan Topalov, ElitsaGieva and GeorgiNikolov, "Air Quality Monitoring in Urban Environments", 39th International Spring Seminar in Electronics Technology (ISSE),2016

8. Santosh G Bhandarakawathe, Prof.S. B. Somani, "A Survey on WiFi Based Air Pollution Monitoring System", International Journal of Innovative Research Computer and Communication Engineering Vol. 5, Issue 3, March
2017

9. Ch.V.Saikumar, M.RejiP.C.Kishoreraja, "IOT based Air Quality Monitoring system",International Journal of Pure and Applied Mathematics Volume 117 No. 9 2017, 53-57

10. Tudose, Dan Stefan, et al. "Mobile sensors in air pollution measurement. "Positioning Navigation and Communication (WPNC), 2011 8th Workshop on. IEEE, 2011.

11. Khodve, Shilpa R., and A. N. Kulkarni. "Web Based Air Pollution Monitoring System (Air Pollution Monitoring Using Smart Phone)." International Journal of Science and Research (IJSR) 5.3 (2016): 266-269. 